\title{
TESTICULAR LIPIDS
}

\section{EFFECT OF SURGERY AND UNILATERAL OR BILATERAL GRYPTORCHIDISM}

\author{
A. D. JOHNSON, W. R. GOMES, M. J. FREE AND \\ N. L. VANDEMARK \\ Animal Reproduction Teaching and Research Center,* \\ The Ohio State University, Columbus, Ohio, U.S.A.
}

\section{(Received 29th August 1967)}

\begin{abstract}
Summary. Testes of thirty mature male rabbits were used to determine the effects of surgery and artificial cryptorchidism on weight and lipid changes in the testes 6 days after treatment. Twelve testes were analysed from each of five groups including: (1) unoperated controls, (2) shamoperated controls, (3) and (4) a unilaterally cryptorchid group which supplied both contralateral scrotal testes and abdominal testes, and (5) a bilaterally cryptorchid group.

Scrotal testes of sham operated and of unilaterally cryptorchid rabbits did not differ significantly from controls in any respect. Unilateral or bilateral cryptorchidism caused a decrease in testis wet and dry weight. Total lipid per testis varied in experimental groups, but total lipid per gram of dry weight was not significantly affected by treatment. Unilaterally cryptorchid testes had higher cholesterol concentrations than the contralateral scrotal testes and the control testes, but the bilaterally cryptorchid testes did not differ significantly from controls. Unilaterally and bilaterally cryptorchid testes increased in esterified cholesterol and lipid phosphorus concentrations. In general, bilateral operations resulted in a response intermediate between the control and comparable unilateral operations.
\end{abstract}

\section{INTRODUCTION}

The role of lipids in physiological and biochemical processes occurring in the testis are poorly understood; however, sterols have been generally implicated as precursors of steroid hormones and other lipids have been reported to be adequate substrates in metabolic processes (Annison, Scott \& Waites, 1963). Furthermore, phospholipids, triglycerides and cholesterol have been found to be constituents of cell membranes (Cuthbert, 1967) and, as such, might qualitatively or quantitatively reflect membrane changes which occur during alterations in testis function.

Changes in testicular lipids have been found following cadmium treatment

* Postal address: Department of Dairy Science, 735 Stadium Drive, Columbus, Ohio 43210. 
(Davis \& Coniglio, 1966; Johnson, VanDemark, Gomes, Butler \& Hodgen, 1967), oestrogen treatment (Lacy, 1960), hypophysectomy (Lynch \& Scott, 1951) and cryptorchidism (Davis \& Coniglio, 1966; Fleeger, Bishop, Gomes \& VanDemark, 1968; Johnson et al., 1967). Several workers have reported that artificial unilateral cryptorchidism produces histological, enzymatic, and lipid changes not only in the abdominal testis, but also in the contralateral scrotal testis (Hoffman, 1960; Clegg, 1965; Fleeger et al., 1968). If this is the case, it should be determined whether these changes are caused by reaction to the testis translocation operation or whether the abdominal testis creates an environment which affects its contralateral scrotal partner. If the abdominal testis is affected by the scrotal organ, then one should determine the effects of cryptorchidism on the abdominal testis without a scrotal partner, i.e. on bilaterally cryptorchid testes. That unilaterally cryptorchid and bilaterally cryptorchid testes differ is suggested by the report of Hayashi, Ogata, Shiraogawa, Murakami \& Tuneishi (1958) who found differences in enzyme activities of unilaterally and bilaterally cryptorchid testes.

The present study was undertaken to measure the effects of surgery and short-term unilateral and bilateral cryptorchidism on testicular histology and lipid levels. Thereby it was planned to determine whether surgical effects exist, whether histology and lipid levels of the scrotal testis are affected by unilateral cryptorchidism, and whether these parameters differ in unilaterally and bilaterally cryptorchid testes.

\section{MATERIALS AND METHODS}

Thirty mature male rabbits of the giant breeds, weighing $3.3 \pm 0.2 \mathrm{~kg}$, were randomly assigned to experimental groups to provide twelve testes for each of five treatment groups: (1) unoperated controls, (2) sham-operated controls, (3) and (4) a unilaterally cryptorchid group which supplied both scrotal and abdominal testes, and (5) a bilaterally cryptorchid group.

In all groups except the controls the animals were anaesthetized with sodium pentobarbital and, when necessary, maintained in surgical anaesthesia with ether. For sham operations, the scrotum, tunica vaginalis and gubernaculum were incised. The testes were washed with saline, passed into the body cavity and allowed to redescend after suturing the tunica vaginalis and the scrotum. Testes which were translocated were handled in the same way except a suture was placed in the inguinal canal to prevent descent. Unilateral operations were alternated between left and right testes. When surgery was performed, sulphanilamide was applied to the incision before suturing the scrotum and 50,000 to 100,000 i.u. of penicillin were administered intramuscularly.

Six days following treatment the animals were anaesthetized and the testes were recovered by a midventral or a scrotal incision. They were trimmed, weighed and a histological sample and duplicate samples for dry weight determinations were taken. The remaining sample was frozen in liquid nitrogen and stored at $-20^{\circ} \mathrm{C}$ until extraction.

Samples taken for histological examination were fixed in Bouin's solution, imbedded in paraffin, and sectioned at a thickness of $5 \mu$. The sections were 


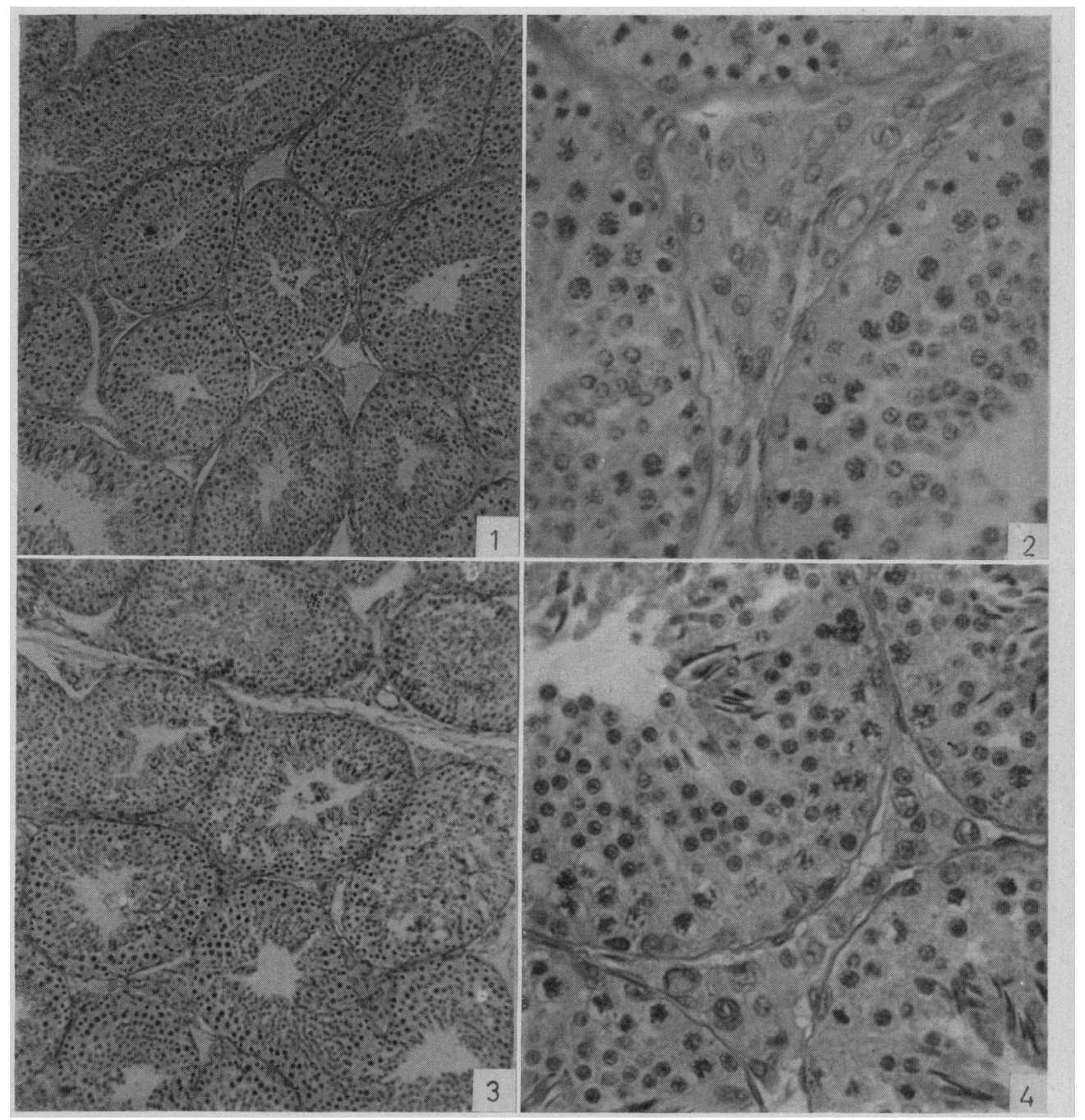

Fis. 1. Testis from antreated control mabit. 89.

Fis. 2. Magnified portion of lig. 1. 3866

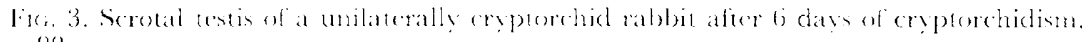
83 .

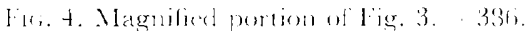


PI. ITF, 2

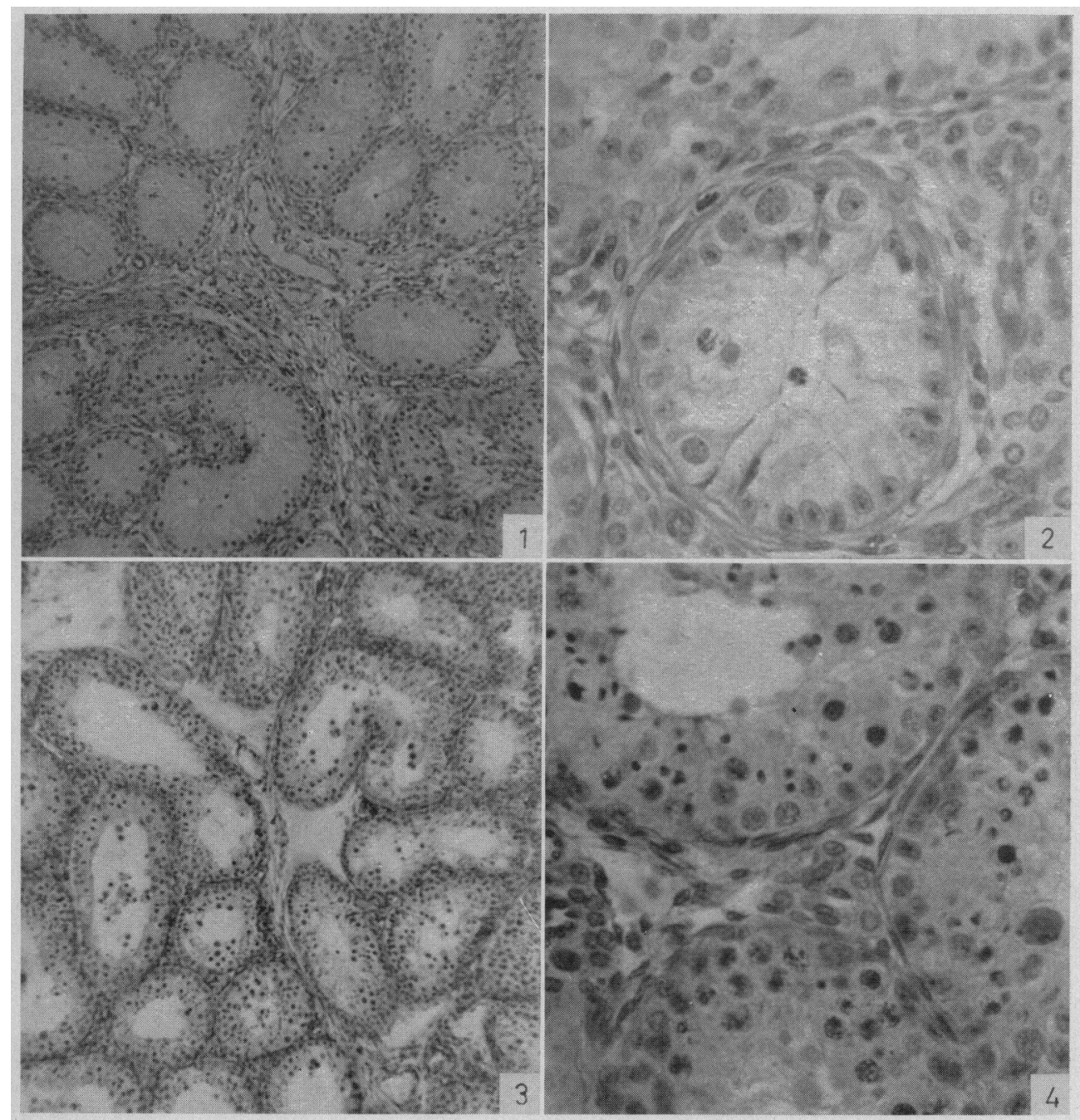

Fro. 1. Abdominal testis of a unilaterally cryptorchid rabbit after fidays of cryptorchidism. $\times 88$.

Fic. 2. Magnified pontion of Fig. 1. $\times 336$.

Fis. 3. Testis from a bilaterally cryptorchid rabbit after 6 days of cryptorchidism. 89.

Fic, 4. Magnified portion ol Fig. 3. ×386. 
stained with periodic acid-Schiff-haematoxylin and examined under the light microscope.

Lipid fractions in testis tissue samples were measured according to the procedures outlined by Fleeger et al. (1968). Treatment differences were analysed statistically by procedures outlined by Steel \& Torrie (1960).

\section{Histology}

\section{RESULTS}

Plate 1 illustrates the histological appearance of scrotal testes from control (Pl. 1, Figs. 1 and 2) and unilaterally cryptorchid (Pl. 1, Figs. 3 and 4) rabbits. Neither the latter testes nor testes from sham-operated rabbits differed histologically from control testes in cell types, tubular size or appearance of the interstitium. Conversely, as shown in Plate 2, the abdominal testes from unilaterally cryptorchid rabbits (Pl. 2, Figs. 1 and 2) exhibited extensive destruction of the germinal epithelium. Most of the tubules contained only Sertoli cells and spermatogonia with occasional light-staining, multinuclear syncytia of spermatids. The interstitial tissue appeared to undergo hypertrophy and hyperplasia in these tissues, but this seemed largely due to an increase in connective tissue. In the bilaterally translocated testes (Pl. 2, Figs. 3 and 4), destruction of the germinal epithelium appeared less advanced. No spermatozoa or later stages of spermatids were present but many large multinuclear syncytia of younger generation spermatids were in evidence and the spermatogonia and early spermatocytes appeared normal in many tubules. Some hyperplasia of the interstitial cells had occurred, but this was generally less marked than in unilaterally translocated testes.

\section{Testis weight}

As shown in Table 1, neither testes from sham-operated rabbits nor scrotal testes from unilaterally cryptorchid rabbits differed from control testes in wet or dry weight. On the other hand, abdominal testes from unilaterally and bilaterally cryptorchid rabbits weighed less $(P<0 \cdot 05)$ than control, sham or scrotal testes. Dry weight changes in all testes closely paralleled wet weight changes (Table 1).

\section{Total lipids}

Levels ( $\mathrm{mg} /$ testis) and concentrations ( $\mathrm{mg} / \mathrm{g}$ dry $\mathrm{wt}$ ) of total lipids are shown in Table 1. Neither the level nor the concentration of lipids differed from control values in sham-operated testes or scrotal testes of unilaterally cryptorchid rabbits. Lipid levels were generally lower and concentrations were higher in abdominal testes of unilaterally cryptorchid animals but neither difference reached significant levels. Bilateral cryptorchidism significantly decreased $(P<0.01)$ lipid levels compared to controls, but correction for testis weight negated this effect.

\section{Cholesterol}

None of the treatments employed affected the levels (mg/testis) of total, free or esterified cholesterol, nor did the concentration of these sterols $(\mathrm{mg} / \mathrm{g}$ dry $\mathrm{wt}$, 
Table 2) differ from controls in scrotal testes from sham-operated or unilaterally cryptorchid rabbits. Concentrations of total and esterified cholesterol were increased $(P<0.05)$ in unilaterally abdominal testes and esterified cholesterol concentration was higher than control levels $(P<0.05)$ in bilaterally abdominal testes (Table 2).

TABLE 1

TESTIS WEIGHT AND TOTAL LIPID EXTRAGT IN TESTES FROM CONTROL AND TREATED ANIMALS!

\begin{tabular}{|c|c|c|c|c|c|}
\hline \multirow[b]{2}{*}{ Treatment } & \multirow{2}{*}{$\begin{array}{c}\text { Body } \\
\text { weight }(k g)\end{array}$} & \multicolumn{2}{|c|}{ Testis weight } & \multicolumn{2}{|c|}{ Total lipid extract } \\
\hline & & Wet $w t(g)$ & Dry zet (mg) & $m g /$ testis & $m g / g d r y w t$ \\
\hline $\begin{array}{l}\text { Control } \\
\text { Sham operation } \\
\text { Unilateral cryptorchidism }\end{array}$ & $\begin{array}{l}3 \cdot 2 \pm 0 \cdot 3 \dagger \\
3 \cdot 3 \pm 0 \cdot 2 \\
3 \cdot 4 \pm 0 \cdot 2\end{array}$ & $\begin{array}{l}2 \cdot 5 \pm 0 \cdot 2 \\
2 \cdot 6 \pm 0 \cdot 1\end{array}$ & $\begin{array}{l}318 \pm 29 \\
311 \pm 20\end{array}$ & $\begin{array}{l}70 \cdot 2 \pm 5 \cdot 6 \\
75 \cdot 8 \pm 5 \cdot 3\end{array}$ & $\begin{array}{l}230 \pm 19 \\
247 \pm 14\end{array}$ \\
\hline $\begin{array}{l}\text { Scrotal } \\
\text { Abdominal } \\
\text { Bilateral cryptorchidism }\end{array}$ & $3.3 \pm 0.2$ & $\begin{array}{l}2 \cdot 7 \pm 0 \cdot 2 \\
2 \cdot 0 \pm 0 \cdot 2^{*} \\
1 \cdot 7 \pm 0 \cdot 2^{* *}\end{array}$ & $\begin{array}{l}330 \pm 26 \\
249 \pm 28^{*} \\
244 \pm 35^{*}\end{array}$ & $\begin{array}{l}76 \cdot 0 \pm 5 \cdot 9 \\
67 \cdot 5 \pm 9 \cdot 3 \\
55 \cdot 4 \pm 3 \cdot 8^{* *}\end{array}$ & $\begin{array}{l}238 \pm 18 \\
273 \pm 26 \\
227 \pm 48\end{array}$ \\
\hline
\end{tabular}

* Significantly different from controls $(P<0 \cdot 05)$.

** Significantly different from controls $(P<0.01)$.

$\dagger$ Mean \pm standard error.

$+n=12$.

TABLE 2

TESTICULAR LIPID CONGENTRATIONS FOLLOWING TREATMENT $\dagger$

\begin{tabular}{|c|c|c|c|c|c|}
\hline \multirow[b]{2}{*}{ Treatment } & \multicolumn{3}{|c|}{ Cholesterol ( $m g / g d r y w t)$} & \multirow{2}{*}{$\begin{array}{c}\text { Lipid } \\
\text { phosphorus } \\
(m g / g \text { dry wt })\end{array}$} & \multirow{2}{*}{$\begin{array}{c}\text { Triglyceride } \\
\text { (Amole/g dry wt) }\end{array}$} \\
\hline & Total & Free & Esterified & & \\
\hline $\begin{array}{l}\text { Control } \\
\text { Sham operation } \\
\text { Unilateral cryptorchidism }\end{array}$ & $\begin{array}{l}18 \cdot 5 \pm 1 \cdot 2 \dagger \\
19 \cdot 5 \pm 1 \cdot 9\end{array}$ & $\begin{array}{l}10 \cdot 5 \pm 1 \cdot 0 \\
10 \cdot 2 \pm 1 \cdot 9\end{array}$ & $\begin{array}{l}8 \cdot 0 \pm 1 \cdot 7 \\
9 \cdot 4 \pm 1 \cdot 6\end{array}$ & $\begin{array}{l}3 \cdot 1 \pm 0 \cdot 5 \\
3 \cdot 2 \pm 0 \cdot 6\end{array}$ & $\begin{array}{l}140 \pm 8 \\
147 \pm 16\end{array}$ \\
\hline $\begin{array}{l}\text { Scrotal } \\
\text { Abdominal } \\
\text { Bilateral cryptorchidism }\end{array}$ & $\begin{array}{l}17 \cdot 5 \pm 1 \cdot 6 \\
28 \cdot 3 \pm 5 \cdot 7 * \\
23 \cdot 3 \pm 3 \cdot 4\end{array}$ & $\begin{array}{r}9 \cdot 8 \pm 1 \cdot 8 \\
13 \cdot 2 \pm 2 \cdot 7 \\
10 \cdot 1 \pm 1 \cdot 5\end{array}$ & $\begin{array}{c}7 \cdot 8 \pm 1 \cdot 4 \\
15 \cdot 2 \pm 4 \cdot 2^{*} \\
13 \cdot 5 \pm 2 \cdot 6^{*}\end{array}$ & $\begin{array}{l}3 \cdot 7 \pm 0 \cdot 6 \\
5 \cdot 1 \pm 0 \cdot 7 * * \\
4 \cdot 9 \pm 1 \cdot 0^{*}\end{array}$ & $\begin{array}{l}130 \pm 17 \\
151 \pm 13 \\
189 \pm 32^{*}\end{array}$ \\
\hline
\end{tabular}

* Significantly different from controls $(P<0 \cdot 05)$.

** Significantly different from controls $(P<0.01)$.

$\dagger$ Mean \pm standard error.

$\pm n=1 \overline{2}$.

Phospholipids and triglycerides

As with the other parameters, scrotal testes from treatment groups did not differ from control testes in lipid phosphorus or triglyceride concentrations (Table 2). Lipid phosphorus was more concentrated in testes from unilaterally $(P<0.01)$ and bilaterally $(P<0.05)$ cryptorchid animals and triglyceride concentrations were increased $(P<0 \cdot 05)$ by bilateral cryptorchidism (Table 2$)$.

\section{DISGUSSION}

The lack of effect of sham operation on any of the parameters measured in this study would suggest that surgery has no effect on testicular lipids. The present data also failed to show a significant effect of unilateral cryptorchidism on the 
testes remaining in the scrotum. This is somewhat surprising as such an effect has been reported from this laboratory (Fleeger et al., 1968) and by others (Hoffman, 1960; Clegg, 1965). Since such changes were not demonstrated here, however, it is difficult to deduce whether the effects shown by other workers were caused by surgical stress.

The decreases in testis weight and total lipid levels and the concurrent increases in cholesterol concentration and esterified:free cholesterol ratio of abdominal testes following cryptorchidism are in general agreement with earlier work (Perlman, 1950; Hoffman, 1960; Fleeger et al., 1968; Johnson et al., 1967). An increase in lipid phosphorus concentration was previously shown by McEnery \& Nelson (1963) in the 80-day cryptorchid rat. Such an increase was not reported by Fleeger $e t$ al. (1968) studying unilaterally cryptorchid animals.

The present study lends support to the contention of Hayashi et al. (1958) that unilaterally cryptorchid testes differ biochemically from bilaterally cryptorchid testes. Hayashi et al. (1958) reported that testes unilaterally translocated to the body cavity exhibit higher levels of lipase activity than do bilaterally translocated testes. Although not significant, the data in the present study suggest that abdominal testes with a scrotal partner are more severely damaged than bilaterally cryptorchid testes and have higher concentrations of total lipid, total, free and esterified cholesterol, and phospholipids. In general, bilateral cryptorchidism resulted in values intermediate between unilaterally cryptorchid testes and scrotal testes.

The differences between the unilateral and bilateral abdominal testes may largely be explained on the basis of circulating gonadotrophin levels and their effect in partially preventing, or at least slowing, testicular degeneration. Since cryptorchidism decreases the androgen producing capacity of the testis (Llaurado \& Dominquez, 1963), one would expect lower levels of the circulating androgens and higher levels of circulating gonadotrophin in bilaterally cryptorchid rabbits than in unilaterally cryptorchid animals. As reported by Wrete (1942) and Butler, Johnson, Gomes \& VanDemark (1967), gonadotrophins decrease the severity of heat-induced damage in the testis. This could explain the histological and biochemical differences reported here.

The reasons for lipid changes during destruction of testicular elements are still unknown; they may simply be due to testicular damage, whatever its cause. It appears, however, that increasing concentrations of total lipid, phospholipid and triglyceride are associated with decreasing proportions of tubular elements, or, conversely, with increasing proportions of interstitial elements. These results suggest either that lipids are normally more concentrated in the interstitium or that tubular elements are normally the site of lipid catabolism.

The changes in cholesterol concentrations and the free: esterified cholesterol ratio, however, may more directly reflect the action of gonadotrophins on the interstitium and the rate of steroid secretion by this portion of the testis (Johnson et al., 1967; Butler et al., 1967). Increases in testicular esterified cholesterol have been reported following treatments which decrease androgen synthesis (Lacy, 1960; Lynch \& Scott, 1951), lending credence to this suggestion. 


\section{ACKNOWLEDGMENTS}

The authors are indebted to T. L. Criblez for assistance in chemical analysis. This research was supported by USPHS Grant Number Gm-12247-03.

\section{REFERENCES}

Annison, E. F., Scotr, T. W. \& Waites, G. M. H. (1963) The role of glucose and acetate in the oxidative metabolism of the testis and epididymis of the ram. Biochem. F. 88, 482 .

Butler, W. R., Johnson, A. D., Gomes, W. R. \& VanDemark, N. L. (1967) Testis lipids after stimulation or inhibition of testicular elements. (Abstract.) F. Dairy Sci. 50, 1005.

CLEGG, E. J. (1965) Studies on artificial cryptorchidism: Compensatory changes in the scrotal testes of the unilaterally cryptorchid rats. $\mathcal{F}$. Endocr. 33, 259.

Cuthrert, A. W. (1967) Membrane lipids and drug action. Pharmac. Rev. 19, 59.

Davis, J. T. \& Coniglio, J. C. (1966) Changes in testicular lipids of rats treated with factors affecting spermatogenesis. Fedn Proc. Fedn Am. Socs exp. Biol. 25, 765.

Fleeger, J. L., Bishop, J. P., Gomes, W. R. \& VanDemark, N. L. (1968) Testicular lipids. I. Effect of unilateral cryptorchidism on lipid classes. F. Reprod. Fert. 15, 1.

Hayashi, M., Ogata, K., Shiraogawa, T., Murakami, Z. \& Tuneishi, S. (1958) The effect of uniIateral and bilateral cryptorchidism upon the activities of $\beta$-glucoronidase, lipase and esterase in the rat testis. Acta pathol. jap. 8, 113. (Abstracted in Biol. Abstr. 38, No. 13748, 1962.)

Hofrman, R. A. (1960) Changes in the testicular cholesterol in the semicryptorchid and the semicastrate rat. U.S. Army Chemical Warfare Labs, Army Chemical Center, Md.

Johnson, A. D., VanDemark, N. L., Gomes, W. R., Butler, W. R. \& Hodgen, G. D. (1967) Effect of antispermatogenic and hormone treatments on testicular cholesterol. Fedn Proc. Fedn Am. Socs exp. Biol. 26, 645.

LACY, D. (1960) Light and electron microscopy and its use in the study of factors influencing spermatogenesis in the rat. $\mathcal{F l} R$. microsc. Soc. 79, 209.

Llaurado, J. G. \& Dominguez, O. V. (1963) The effect of cryptorchidism on testicular enzymes involved in androgen biosynthesis. Endocrinology, 72, 292.

Lynch, K. M. \& Scotr, W. W. (1951) Lipid distribution in the Sertoli cell and Leydig cell of the rat testis as related to experimental alterations of the pituitary-gonad system. Endocrinology, 49, 8.

MCEneRY, W. B. \& NeLson, W. O. (1953) Organic phosphorus compounds in the testis of the rat under experimental conditions which impair spermatogenesis. Endocrinology, 52, 104.

Perlman, P. L. (1950) The functional significance of testis cholesterol in the rat: Histochemical observations on testes following hypophysectomy and experimental cryptorchidism. Endocrinology, 46, 347.

Steel, R. G. D. \& Torrie, J. H. (1960) Principles and procedures of statistics. McGraw-Hill, New York.

WRETE, M. (1942) Experimentelle Untersuchungen uber Kombinierte Einwirkung von hoher Lufttemperatur und gonadotropen Hormon auf die Hoden. Uppsala LäkFör. Förh. 49, 165. 